University of Nebraska - Lincoln

DigitalCommons@University of Nebraska - Lincoln

Faculty Publications, Department of Psychology

Psychology, Department of

2008

Parenting Styles and Youth Well-Being Across Immigrant

Generations

Anne Driscoll

University of California, Davis

Stephen Russell

The University of Arizona, Tucson

Lisa J. Crockett

University of Nebraska-Lincoln, ecrockett1@unl.edu

Follow this and additional works at: https://digitalcommons.unl.edu/psychfacpub

Part of the Psychiatry and Psychology Commons

Driscoll, Anne; Russell, Stephen; and Crockett, Lisa J., "Parenting Styles and Youth Well-Being Across Immigrant Generations" (2008). Faculty Publications, Department of Psychology. 352.

https://digitalcommons.unl.edu/psychfacpub/352

This Article is brought to you for free and open access by the Psychology, Department of at DigitalCommons@University of Nebraska - Lincoln. It has been accepted for inclusion in Faculty Publications, Department of Psychology by an authorized administrator of DigitalCommons@University of Nebraska - Lincoln. 


\title{
Parenting Styles and Youth Well-Being Across Immigrant Generations
}

\author{
Anne K. Driscoll, University of California, Davis \\ Stephen T. Russell, The University of Arizona, Tucson \\ Lisa J. Crockett, University of Nebraska-Lincoln
}

\begin{abstract}
This study examines generational patterns of parenting styles, the relationships between parenting styles and adolescent well-being among youth of Mexican origin, and the role of generational parenting style patterns in explaining generational patterns in youth behavior (delinquency and alcohol problems) and psychological well-being (depression and self-esteem). This study uses two waves of data from the National Longitudinal Study of Adolescent Health (Add Health). The proportion of teens with permissive parents increased with generation; other parenting styles declined. The rate of youth with behavioral problems increased with generation. Self-esteem improved with generation; depression scores did not. Bivariate generational patterns of behavioral and psychological outcomes are a function of the patterns seen for youth with permissive parents, coupled with the increase in the proportion of permissive parents with each successive generation. In contrast, these outcomes did not worsen with generation for youth with authoritative parents.
\end{abstract}

Keywords: parenting, acculturation, adolescents, generation

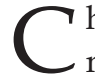

hildren from immigrant families make up a rapidly growing segment of the youth population in the United States (U.S. Census Bureau, 2000). One in five U.S. children is from an immigrant family, raised by at least one immigrant parent (Jamieson, Curry, \& Martinez, 2001). Most of these youth are Latino or Asian; among youth from immigrant families, Latinos are at particular risk for negative outcomes. Their experiences differ from those of non-Latino Whites and African Americans, the majority of whom are the U.S.-born children of native-born parents. Although Latino children have distinct experiences, parenting is uni- 
versally important in shaping child and adolescent well-being; research consistently shows that parenting practices and styles are linked to the behavioral and emotional development of teens. At the same time, immigration and acculturation processes affect parents' childrearing styles and parent-child relationships.

Most Latino youth are U.S. born, yet most are being raised by immigrant parents. Nearly one in five Latino elementary and high school students $(18 \%)$ is an immigrant; almost half $(48 \%)$ belong to the second generation, and the rest are the U.S.-born children of U.S.-born parents (Jamieson et al., 2001). Latino youth are likely to have less-educated parents and live in poverty; they often live in communities and attend schools with few resources and opportunities; and they may suffer discrimination based on ethnicity, skin color, and language. Research on immigrant families indicates that the acculturation process influences the emotional and behavioral outcomes of first-, second-, and higher-generation Latino youth. Inevitably, it also influences the values and behaviors of parents; that is, culture shapes how parents parent their children and what kinds of relationships parents have with their children (Kao, 2004; Pong, Hao, \& Gardner, 2005). Thus, acculturation influences youth well-being through its direct influence on teens and through its indirect effects on their parents.

In general, parental warmth and support are thought to positively influence emotional well-being (Conger et al., 1993; Kurdek \& Fine, 1994), whereas moderate levels of parental control are thought to be protective against harmful and delinquent behaviors among adolescents (Baumrind, 1991; Maccoby \& Martin, 1983). High levels of parental warmth and support are associated with greater self-esteem and lower depression and anxiety (Ge, Best, Conger, \& Simons, 1996). Teens whose parents exercise more control over their teens' activities are less likely to engage in delinquent behaviors (Jacobson \& Crockett, 2000; Patterson \& Stouthamer-Loeber, 1984), smoke, use alcohol or other drugs (Brown, Mounts, Lamborn,

This research was funded by National Institute of Child Health and Human Development Grant No. HD R01 039438, to Lisa J. Crockett and Stephen T. Russell. It uses data from the National Longitudinal Study of Adolescent Health (Add Health), a project designed by J. Richard Udry, Peter S. Bearman, and Kathleen Mullan Harris and funded by National Institute of Child Health and Human Development Grant No. P01HD31921, with cooperative funding from 17 other agencies. Special acknowledgment is due to Ronald R. Rindfuss and Barbara Entwisle for assistance in the original design. Persons interested in obtaining data files should contact Add Health, Carolina Population Center, 123 W. Franklin Street, Chapel Hill, NC 27516-2524; Web site: http:/ / www. cpc.unc.edu/projects/addhealth. 
\& Steinberg, 1993; Shakib et al., 2003), and engage in sexually risky behavior (Hogan \& Kitagawa, 1985; Jacobson \& Crockett, 2000; Newcomer \& Udry, 1987). Latino youth are no exception to these patterns.

Using a nationally representative sample of Mexican-origin youth and their parents, we examine patterns of parenting styles across immigrant generations to better understand the relationships between parenting styles and adolescent well-being among Mexican American youth. Central to our investigation is the role of generational parenting style patterns in explaining generational patterns in youth behavior and well-being.

\section{Parenting Styles and Adolescent Well-Being}

Parenting practices have been repeatedly linked to adolescent wellbeing. The levels of support and warmth that parents show towards their children influence youth emotional well-being; children who feel loved and accepted are happier and more confident (Gray \& Steinberg, 1999; Wolfradt, Hemple, \& Miles, 2003). In addition, parental supervision is linked to adolescent behavior; parents who control their children through supervision and monitoring restrict their opportunities to engage in risky behavior (Harris, 2000; Hogan \& Kitagawa, 1985).

Based on the two dimensions of support and control, four types of parenting style have been identified: authoritative, authoritarian, indulgent or permissive, and neglectful or disengaged (Maccoby \& Martin, 1983; see Table 1). Authoritative parents combine high support and responsiveness (warmth and sensitivity to the child's needs) with supervision and firm expectations for behavior. This combination of strong support and control is positively related to psychological well-being in children and adolescents (Baumrind, 1991; Maccoby \& Martin, 1983), higher self-reliance and social competence, and lower psychological distress and problem behavior among adolescents (Lamborn, Mounts, Steinberg, \& Dornbusch, 1991). In contrast, authoritarian parenting (low responsiveness and support combined with high levels of control), indulgent or permissive parenting (high responsiveness and low levels of control), and neglectful or disengaged parenting (low responsiveness and low levels of control) are typically associated with poorer psychological and behavioral outcomes. This pattern generally holds across ethnicity, socioeconomic status, and family structure (Steinberg, 2001; Steinberg, Mounts, Lamborn \& Dornbusch, 1991). Teens with disengaged parents are particularly at risk for poor mental health outcomes and academic attitudes and achievement (Radziszewska, Richardson, Dent, \& Flay, 1996; Shucksmith, Hendry, \& 
Table 1. Construction of Parenting Style Categories

\begin{tabular}{lcc}
\hline & Support & Control \\
\hline Permissive & High & Low \\
Disengaged & Low & Low \\
Authoritative & High & High \\
Authoritarian & Low & High \\
& & \\
\hline
\end{tabular}

Glendinning, 1995). Drawing on previous work, we hypothesize that Mexican-origin youth with parents who exercise firm control (authoritative and authoritarian) will have fewer behavior problems and that teens with supportive parents (authoritative and permissive) will have better emotional well-being.

\section{Acculturation and Adolescent Well-Being}

The straight-line assimilation model was developed to explain the experiences of European immigrants who arrived in the late 1800s and early 1900s and their children and grandchildren. It assumes that first-generation immigrants, having been socialized and educated in their home countries, remain tied to their cultures of origin but that their native-born children more readily adopt the culture, language, values, and behaviors of the receiving society while retaining some ties to the home cultures through their immigrant parents. The grandchildren of immigrants have no direct ties to the countries of origin and thus differ little, if at all, from those from majority-culture families living in the United States for many generations (Gordon, 1964; Warner \& Srole, 1945). This progression toward becoming American implicitly predicts that educational attainment, occupational status, and income improve with generation as people become increasingly integrated into the larger society. In addition, the stress of moving to a new country, struggling with an unfamiliar language and set of customs, and breaking social and familial ties results in lower psychological well-being among immigrants than among their children and grandchildren (Handlin, 1951; Harker, 2001).

Changes in various aspects of immigration patterns since the 1960sincluding a shift from Europe as the primary region of immigrant origin to Latin America and Asia, as well as changes in the economy and workforce that more recent immigrants have encountered upon arrival-have prompted a reexamination of the straight-line assimilation model (Buriel \& 
De Ment, 1997). Some work suggests that the pattern of assimilation and improvement seen for some earlier immigrants does not uniformly hold for more recent immigrants from Latin America and Asia and their descendants. Instead, much of the research indicates that although immigrant families and communities protect their children against harmful influences from the wider society, this protection is eroded as the attitudes and values of parents and children become similar to those of the majority culture through lengthening exposure to it (Denner, Kirby, Coyle, \& Brindis, 2001; Fuligni, Tseng, \& Lam, 1999). Thus, the prevalence of negative outcomes has been found to rise with immigrant generation and level of acculturation.

Most of the work on this topic has found that more acculturated youth have more negative behavior outcomes than do immigrants, a pattern attributed to greater exposure to the more permissive majority culture. For example, highly acculturated Latino teens are more likely to smoke cigarettes and use marijuana and other drugs than are teens who are more oriented to their cultures of origin (Epstein, Botvin, \& Diaz, 1998, 2001). Length of residence in the United States is positively associated with drinking alcohol and suffering from alcohol-related problems (Gil, Wagner, \& Vega, 2000), and level of acculturation is positively associated with delinquent behavior (Samaniego \& Gonzales, 1999). In addition, more acculturated Latinas are younger at first sex and have more sexual partners than do less acculturated Latina teens (C. P. Kaplan, Erickson \& Juarez-Reyes, 2002).

The relationship among generation and acculturation and psychological well-being is less clear. Among adults of Mexican origin, immigrants tend to have lower levels of depression and other mental illnesses than do natives (Burnam, Hough, Karno, Escobar, \& Telles, 1987; M. S. Kaplan \& Marks, 1990; Shrout et al., 1992). More acculturated individuals may have weaker ties to ethnic social support as well as higher but unmet expectations for achieving social and economic status. The findings for adolescents are less uniform. For example, among youth in the Longitudinal Study of Adolescent Health (Add Health), mean level of depressive symptoms increased with generation for Chinese, Mexican, and Central and South American youth but declined for Filipinos (Harker, 2001). No clear linear patterns of positive well-being across generations were found for any national origin groups. Self-esteem appears to be an exception to this mixed generational pattern. Among Asians and Latinos, more acculturated and higher-generation youth have higher self-esteem than do less acculturated and first- and second- generation youth (Bankston \& Zhou, 2002; Dinh, Roosa, Tein \& Lopez, 2002). Lower self-esteem among youth from immigrant families may be due to higher rates of stress and anxiety 
among Asians and Latinos with immigrant parents, stemming from the need to balance their parents' cultures with the dominant culture. Controlling for stress and anxiety erased the generational pattern of higher selfesteem among the children of U.S.-born parents. This pattern also appears among youth whose families immigrated to Europe, suggesting that lower self-esteem among immigrants is not specific to certain cultures of origin or destination but may be related to what is universal about the immigrant experience (Sam, 2000).

The finding that acculturation may be associated with negative outcomes among adolescents prompted social scientists to revisit earlier models that equated adaptation to U.S. culture with improved economic, educational, and social outcomes. Cultures in many of the countries of origin of Latino and Asian immigrants stress the importance of family ties, support, and obligations to a greater extent than does mainstream U.S. culture, which places a higher value on independence and autonomy. Some research suggests that these cultural features benefit immigrant youth because they, along with close-knit immigrant communities that reinforce cultural ties and values, protect young people from harmful influences (Denner et al., 2001; Zhou, 1994). Based on the literature, our hypothesis is that higher-generation youth - particularly, those with native-born parents - will have more problem behaviors than will immigrant youth and those with immigrant parents. In addition, we predict that although levels of depression will decline with generation, an opposite pattern will emerge for self-esteem.

\section{Acculturation and Parenting}

In addition to these social and economic differences, cultural differences undoubtedly account for some portion of the difference in parenting styles between Latino and White parents. The dominant U.S. culture values independence and autonomy to a greater degree than do Latino cultures, which emphasize interdependence and the importance of family ties and obligations. Thus, Latino parents may exercise greater control over their adolescent offspring to reinforce the primacy of family. Traditional Latino cultures also emphasize rights and responsibilities among family members based on age and sex. Such an emphasis tends to foster authoritarian parenting in which exercising control over children is a key element; in comparison, parents from the dominant culture may be more permissive and less controlling of their adolescent children in an effort to foster autonomy and a sense of independence (Bulcroft, Carmody, \& Bulcroft, 1996). 
This literature suggests that parenting practices and parenting styles may gradually change with each successive generation in the United States. In fact, research on Latino parenting practices suggests that parenting styles change with generation in response to increasing distance from the culture of origin and the need to adjust to the society in which parents are raising their children. Parents' socialization practices gradually shift from an emphasis on interdependence to one stressing individualism (Delgado- Gaitan, 1994). Immigrant Mexican parents are stricter and expect greater responsibility from their children than do U.S.-born parents, and immigrant mothers are less supportive than their native-born counterparts (Buriel, 1993). These patterns in parenting practices across generations may explain some portion of the link between acculturation among youth and greater participation in risky behaviors. Parental acculturation to dominant U.S. parenting practices may result in the deterioration of protective Latino family values and behaviors, thereby exposing young people to risky external influences (Gil et al., 2000).

In addition to processes of cultural adaptation, families' economic and social situations shape parenting practices. One factor that may affect how much autonomy Latino parents grant their children is their view of threats to their values and to their children's well-being outside the family. White families are more likely to view external institutions in society, such as schools, houses of worship, workplaces, and law enforcement, as reinforcing their own values and thus do not fear the influence of these actors on their children. Moreover, they are less likely to live in dangerous neighborhoods or face discrimination. In comparison, minority parents are more likely to view community institutions as counteracting their values or as being dangerous to their children. Moreover, they are more likely to live in unsafe neighborhoods and to fear discrimination. Thus, they may exercise more control over their children's behavior in an effort to shield them from external perils (Bulcroft et al., 1996; Varela et al., 2004).

In sum, higher-generation Latino youth have poorer outcomes across diverse measures of well-being, perhaps because their parents' parenting styles and practices, which strongly influence these outcomes, change with the process of acculturation. We examine generational differences in parenting as possible explanations for generational patterns of behavioral and mental health outcomes among teens of Mexican origin, the largest nationalorigin subgroup of Latino youth. Specifically, we expect generational differences in adolescent well-being such that first-generation Mexican youth are protected in terms of emotional well-being (depression and self-esteem) and problem behaviors (delinquency and alcohol-related problems). We also 
expect generational differences in parenting styles: Immigrant parents are likely to be less permissive than their U.S.-born counterparts but more likely to be authoritative or authoritarian. Finally, we expect parenting styles to be associated with adolescent well-being for all generations, but generational differences to be explained by generational changes in parenting style.

\section{Method}

\section{Data}

This study uses Waves 1 and 2 of Add Health, the most recent comprehensive study of adolescents in the United States. The sampling frame included all high schools in the United States, as well as their largest feeder schools. More than 12,000 adolescents in Grades 7 to 12 were participants in the nationally representative core of the in-home survey (Bearman, Jones, \& Udry, 1997).

The study sample consists of respondents who were 12 to 18 years old at the first interview (Time 1), who identified themselves as Latino and of Mexican origin or descent, and who completed a second interview (Time 2 ) approximately 1 year later. Because the focus of this study is on parenting, one respondent was randomly chosen in households in which more than one youth participated in order to avoid overrepresentation of parents with more than one child.

\section{Outcomes}

Two behavioral and two psychological outcomes are examined. Each was measured at Wave 2 .

Alcohol problems. The alcohol problems measure assessed whether respondents reported experiencing alcohol-related problems in the past 12 months (getting in trouble with parents, in school, with friends, or with a boyfriend or girlfriend; experiencing physical reactions, such as being sick or hung over; or being involved in a situation that they later regretted). Values on this measure ranged from 0 to 26 ; but two thirds $(66.9 \%)$ of the sample reported no alcohol-related problems, and $90.5 \%$ reported 0 to 5 problems. The skewed distribution of this variable violates the assumptions of a normal distribution on which interpretation of ordinary least square multiple regressions are based. Therefore, this variable was transformed via a square root transformation, which converts the distribution of the variable to a more normal form by reducing the relative spacing of 
scores on the right side of the distribution more than the scores on the left side. A square root transformation was chosen because none of the values are less than 0 and none are between 0 and 1 .

Delinquency. The scale measuring delinquency consists of 14 items ranging from graffiti to stealing. Respondents were asked how often they committed any of the acts in the past 12 months. To deal with the skewed distribution of the scale, it was also transformed by taking the square root of the measure.

Depression. Depression was measured using a seven-item scale derived from the Center for Epidemiologic Studies Depression Scale (Radloff, 1977), based on questions about the last week. This scale was further validated for use with youth of Mexican origin (Crockett, Randall, Shen, Russell, \& Driscoll, 2005). Questions include "You were bothered by things that usually don't bother you," "You felt depressed," "You felt lonely," and "You felt sad." Responses are coded from 0 (never or rarely) to 3 (most of the time or all of the time). Cronbach's alpha is .82.

Self-esteem. The self-esteem scale consists of six items based on the Rosenberg Self-Esteem Scale (Rosenberg, 1989), including "I like me just the way I am," "I have a lot of energy," and "I have a lot of good qualities." Responses range from 1 (strongly disagree) to 5 (strongly agree). Cronbach's alpha is .84 .

\section{Independent Variables}

The key independent variables in this study are immigrant generation and parenting style. Both were measured at Wave 1 .

Immigrant generation. First-generation immigrants are respondents who were born abroad and moved to the United States. Second-generation immigrants were born in the United States to at least one foreign-born parent, and third-generation immigrants (and higher) were born in the United States to two U.S.-born parents.

Parenting style. Parenting style is measured using parental control and maternal support; each measure is based on reports by the teen respondents. For each resident mother, adolescents responded to five items indexing the level of maternal warmth and caring (e.g., "How much do you think your mother cares about you?"). Drawing on the approach used by Ellis, Thomas, and Rollins (1976), comparable scales were created. The use of these measures is similar to that employed by Regnerus and Bur- 
dette (2006). These items are averaged to create a support scale for each teen's mother. Cronbach's alpha for the maternal support scale is .84. Adolescents were asked if their parents let them make their own decisions about such issues as "the time you must be home on weekend nights," "the people you hang around with," and "what you wear." The six items were averaged to create a total score, with a high score reflecting greater autonomy - that is, less parental control. Cronbach's alpha for this scale is .63. Although the alpha for this scale is somewhat lower than ideal, the six items form one factor with sufficiently high loadings.

Parenting style categories were constructed using levels of parental control and support received from mothers. Paternal support was not included, because a large proportion of the sample did not have a resident father, whereas nearly every respondent had a resident mother. Averaging support for youth with two parents would result in unequal comparisons between students with one parent and those with two. Four categories were constructed. Youth who rated their parents below the median level of control were assigned to the low parental control category; those who rated their parents at or above the median level formed the high parental control category. The measures of maternal support were highly skewed to the higher end. Therefore, those who scored greater than 4 on a scale of 1 to 5 were placed in the high support category; those who scored 4 or lower were placed in the low support category. This approach to the highly skewed nature of the parental support measure mirrors that used with Add Health data (Kapinus \& Gorman, 2004). Those who rated their parents low on control and high on support compose the permissive category; those who rated their parents low on control and low on support compose the disengaged category. The authoritative category includes respondents who rated their parents as being supportive and exercising high levels of control. The final category, authoritarian, comprises youth who rated their parents as exercising high levels of control and offering low levels of support.

Background characteristics. Respondent age, family structure and size, and socioeconomic status are included to control for variation in background characteristics. Family structure was measured by whether teens reported living with both parents (reference category), in a stepfamily, or with a single parent. Socioeconomic status was measured using parental education and family public assistance status. Parental education is a continuous variable that reflects the number of years of schooling of the most educated parent; public assistance receipt incorporates information, reported by parents, on whether teens' families received cash assis- 
tance, food stamps, or subsidized housing. Number of siblings, reported by teens, is measured via a continuous variable and controls for the effects of siblings on parent-child relationships and the decline in fertility across generations. To address the possibility that parents' behavior is affected by their perceptions of their communities, parents' assessments of their neighborhoods were measured using their descriptions of the levels of crime, drug use, and trash in their neighborhoods. All control variables were measured at Wave 1.

\section{Analyses}

To address generational differences in adolescent well-being and parenting styles, we present descriptive analyses to test the differences in behavioral and psychological outcomes across immigrant generations and across categories of parenting style. The multivariate models address whether generational differences in emotional well-being and problem behaviors can be explained by generational differences in parenting style. The first set of multivariate ordinary least square regression models are direct-effects models that estimated the associations between generation and the outcomes and between parenting styles and the outcomes. The second set of models include interactions between parenting style and immigrant generation, which tested whether the association between generations and the outcome was conditional on parenting style - that is, whether generational patterns of outcomes varied by parenting style. Each model includes background characteristics as controls. For each interaction model, results are presented with second-generation and then third-generation teens as the reference group to illustrate comparisons between all three generations. All analyses were run using the statistical package SUDAAN 9 (RTI International, Research Triangle Park, NC), which adjusts standard errors for the clustered sample design of Add Health.

\section{Sample}

Table 2 describes the sample by presenting means and percentages of the controls included in the multivariate analyses for the sample as a whole and by generation. The mean age of the sample is 14.9 years, and $50.2 \%$ is female. Almost two thirds (62.6\%) lived with both parents; this percentage was higher for second-generation youth $(72.5 \%)$ and lower for third-generation youth (53.3\%). Third-generation teens were most likely to live with a single mother. Parental education varied greatly by generation. Two thirds $(68.1 \%)$ of the parents of first-generation teens and half $(51.8 \%)$ 
Table 2. Sample Description

\begin{tabular}{|c|c|c|c|c|}
\hline & All & $\begin{array}{c}\text { First } \\
\text { Generation }\end{array}$ & $\begin{array}{c}\text { Second } \\
\text { Generation }\end{array}$ & $\begin{array}{l}\text { Third } \\
\text { Generation }\end{array}$ \\
\hline Age $(M)$ & 14.9 & 15.4 & 15.0 & 14.6 \\
\hline Female $(\%)$ & 50.2 & 52.7 & 49.6 & 49.2 \\
\hline \multicolumn{5}{|l|}{ Family structure (\%) } \\
\hline Two parents & 62.6 & 62.0 & 72.5 & 53.3 \\
\hline Single parent & 24.0 & 22.4 & 17.9 & 31.2 \\
\hline Stepfamily & 13.3 & 15.7 & 9.6 & 15.6 \\
\hline \multicolumn{5}{|l|}{ Parental education (\%) } \\
\hline$<$ High school & 42.7 & 68.1 & 51.8 & 18.7 \\
\hline High school & 26.1 & 15.6 & 19.4 & 38.9 \\
\hline Some post-high school & 11.3 & 2.5 & 9.2 & 18.6 \\
\hline$\geq$ Bachelor's degree & 11.8 & 5.0 & 8.6 & 19.0 \\
\hline Missing & 8.0 & 8.7 & 11.0 & 4.8 \\
\hline Siblings (M) & 2.01 & 2.39 & 2.19 & 1.62 \\
\hline \multicolumn{5}{|l|}{ Public assistance (\%) } \\
\hline Yes & 17.6 & 18.4 & 16.9 & 17.8 \\
\hline No & 64.3 & 56.4 & 66.3 & 67.1 \\
\hline Missing & 18.0 & 25.1 & 16.7 & 15.1 \\
\hline \multicolumn{5}{|l|}{ Neighborhood quality (\%) } \\
\hline Good & 37.1 & 32.2 & 36.5 & 40.6 \\
\hline Fair & 14.0 & 14.2 & 12.6 & 15.3 \\
\hline Poor & 29.9 & 26.4 & 34.0 & 27.9 \\
\hline Missing & 19.0 & 27.2 & 16.9 & 16.2 \\
\hline$n$ & 873 & 162 & 415 & 296 \\
\hline Weighted (\%) & 100.0 & 23.3 & 37.9 & 38.9 \\
\hline
\end{tabular}

of the parents of second-generation teens had less than a high school education, compared to only one fifth $(18.7 \%)$ of those whose parents were U.S. born. The mean number of siblings declined with generation. The proportion of teens whose families received public assistance was stable across generations, whereas those who rated their neighborhoods as good rose somewhat with generation.

\section{Descriptive Results}

Behavioral problems were significantly more prevalent among U.S.born Mexican youth - that is, second- and third-generation teens-than among immigrant youth (Table 3). In contrast, self-esteem improved with higher generation; third-generation teens had higher mean self-esteem 
Table 3. Mental Health and Behavioral Outcomes by Immigrant Generation and Parenting Style

\begin{tabular}{|c|c|c|c|c|}
\hline & \multicolumn{2}{|c|}{ Mental Health Outcomes } & \multicolumn{2}{|c|}{ Behavioral Outcomes } \\
\hline & $\begin{array}{l}\text { Self-Esteem } \\
(0-30)\end{array}$ & $\begin{array}{l}\text { Depression } \\
\quad(0-7)\end{array}$ & $\begin{array}{c}\text { Delinquency } \\
(0-37)\end{array}$ & $\begin{array}{l}\text { Alcohol Problems } \\
(0-26)\end{array}$ \\
\hline \multicolumn{5}{|l|}{ Generation } \\
\hline First & 23.3 & 0.57 & 2.5 & 1.0 \\
\hline Second & 23.9 & 0.63 & 3.8 & 1.5 \\
\hline Third & 24.8 & 0.66 & 4.4 & 2.0 \\
\hline Generational differences & $\begin{aligned} 1 \text { st } & <3 \mathrm{rd}^{* *} \\
2 \text { nd } & <3 \mathrm{rd}^{* * *}\end{aligned}$ & & $\begin{array}{l}1 \text { st }<2 \text { nd }^{* * *} \\
1 \text { st }<3 \mathrm{rd}^{* * *}\end{array}$ & 1 st $<3 \mathrm{rd}^{*}$ \\
\hline \multicolumn{5}{|l|}{ Parenting style } \\
\hline 1. Permissive & 24.7 & 0.58 & 3.7 & 1.7 \\
\hline 2. Disengaged & 22.3 & 0.78 & 4.5 & 1.8 \\
\hline 3. Authoritative & 24.8 & 0.57 & 3.1 & 1.3 \\
\hline 4. Authoritarian & 20.5 & 0.88 & 4.6 & 0.9 \\
\hline Parenting style differences & $\begin{array}{c}1,2,3>4^{* * *} \\
1,3<2^{* * *}\end{array}$ & $1,3<2,4^{* * *}$ & $3<4^{*} 1<4^{*}$ & \\
\hline$M$ & 24.1 & 0.63 & 3.7 & 1.5 \\
\hline$n$ & 818 & 820 & 807 & 818 \\
\hline
\end{tabular}

${ }^{*} p \leq .05 ;{ }^{* *} p \leq .01 ;{ }^{* * *} p \leq .001$

than that of first- and second-generation youth. There was no significant difference in mean depression scores across generation.

At the bivariate level, youth with authoritative or permissive mothers had higher self-esteem and lower levels of depressive symptoms than did teens whose mothers fell into one of the nonsupportive categories. Teens with permissive mothers were more likely to have experienced alcoholrelated problems than were those with authoritarian parents. (Higher percentages of youth whose mothers exercised looser control reported problems related to alcohol than did those from families in which the mothers exerted greater control over their children, but the difference was not always statistically significant.) Although teens with authoritative mothers had lower mean delinquency scores than did other teens, the difference was not always statistically significant.

Table 4 shows the distribution of parenting styles by adolescent generation. The proportion of teens who rated their mothers as being permissive was higher for those with U.S.-born parents than for those with immigrant parents; all other parenting styles were lower in the third generation than in the first. Almost two in five first- and second-generation teens de- 
Table 4. Distribution of Parenting Styles within Immigrant Generations (in Percentages)

\begin{tabular}{lrrrr}
\hline & Permissive & Disengaged & Authoritative Authoritarian \\
\hline Generation* & & & & \\
$\quad$ First & 38.0 & 11.5 & 37.8 & 12.7 \\
Second & 38.3 & 12.8 & 37.7 & 11.1 \\
$\quad$ Third & 55.9 & 8.5 & 31.5 & 4.1 \\
Whites & 53.5 & 14.2 & 26.8 & 5.4 \\
Total & 45.0 & 10.8 & 35.4 & 8.8 \\
\hline
\end{tabular}

${ }^{*} p \leq .05$

scribed their mothers as being permissive, as did half of third-generation youth (a 47\% increase). The results indicate that U.S.-born mothers are much more likely to be permissive than immigrant mothers, whereas the proportion who are authoritative is lower among U.S.-born mothers than among immigrant mothers.

For illustrative purposes, the distribution of parenting styles among third- and higher-generation non-Latino White teens is presented at the bottom of Table 4 . The pattern of parenting styles of the U.S.-born mothers of third-generation Mexican teens is remarkably similar to that of the mothers of White teens, suggesting that the parenting styles of Latino mothers become increasingly Americanized with generation.

\section{Multivariate Results}

The direct-effects multivariate models estimate the associations between generations and the outcomes controlling for background characteristics. The interaction models test whether the overall generational patterns in behavioral and mental health outcomes seen at the bivariate level and in the direct-effects models vary by parenting style. These models address the question of whether generational patterns of the outcomes are due to generational differences in parenting styles. Table 5 presents the results of the main effects models; Table 6 presents the results of the interaction regression models predicting the four outcomes of interest. The interaction term in each model interacts generation by maternal parenting style resulting in a 12-level term. To present the results in a clear fashion, each model was run multiple times, with the reference category for the interaction term changed each time. In this way, comparisons can be made across generations within each parenting type. In addition, within each parenting type, three comparisons were made among the three generations. First, 
Table 5. Ordinary Least Squares Regression Models Predicting Emotional Well-Being and Problem Behaviors

\begin{tabular}{|c|c|c|c|c|}
\hline & $\begin{array}{l}\text { Self- } \\
\text { Esteem }\end{array}$ & Depression & Delinquency & $\begin{array}{l}\text { Alcohol } \\
\text { Problems }\end{array}$ \\
\hline \multicolumn{5}{|l|}{ Generation } \\
\hline First & $-.21^{*}$ & -.10 & $-.40^{* *}$ & $-.49^{* * *}$ \\
\hline Second & $-.16^{* *}$ & -.04 & -.14 & -.18 \\
\hline Third & - & - & - & - \\
\hline First versus second & ns & ns & $p<.05$ & $p<.05$ \\
\hline Male & $.14^{*}$ & $-.26^{* *}$ & $.29 * *$ & .18 \\
\hline Age & -.00 & -.01 & $-.07^{*}$ & .05 \\
\hline \multicolumn{5}{|l|}{ Family structure } \\
\hline Single mom & $-.13^{*}$ & .04 & .31 & $.30^{*}$ \\
\hline Stepfamily & -.05 & .05 & .07 & $.42^{*}$ \\
\hline \multicolumn{5}{|l|}{ Parent education } \\
\hline$<$ High school & -.02 & .02 & $.27^{*}$ & .25 \\
\hline Some college & .01 & -.14 & .52 & .23 \\
\hline$\geq$ Bachelor's & .08 & -.13 & .16 & .08 \\
\hline Siblings & .02 & -.02 & -.03 & -.00 \\
\hline Public aid & .07 & -.10 & -.03 & -.06 \\
\hline \multicolumn{5}{|l|}{ Neighborhood } \\
\hline Good quality & .02 & .01 & .05 & -.08 \\
\hline Poor quality & -.02 & .02 & .16 & -.13 \\
\hline Intercept & $4.09 * * *$ & $1.02^{* * *}$ & $2.27^{* * *}$ & -0.17 \\
\hline$R^{2} .05$ & .09 & .10 & .08 & \\
\hline$n 803$ & 804 & 792 & 802 & \\
\hline
\end{tabular}

${ }^{*} p \leq .05 ;{ }^{* *} p \leq .01 ;{ }^{* * *} p \leq .001$

third-generation respondents were the reference group, allowing comparisons to first- and second-generation teens. Next, second-generation teens were the reference group, allowing a third comparison between first- and second-generation respondents. To best capture the patterns found for each maternal parenting type, the results for the interaction results are discussed below by parenting type, not by outcome of interest.

Controlling for background factors rarely changed the generational patterns seen for the outcomes in Table 3 (cf. Table 5). Net of controls, first- and second-generation youth still had lower levels of self-esteem than did those with U.S.-born parents, and there were no differences in mean levels of depression across generations. Immigrant youth had significantly lower levels of delinquency and alcohol-related problems than U.S.-born youth had. 
Table 6. Interaction Ordinary Least Squares Regression Models Predicting Mental Health and Behavioral Outcomes

\begin{tabular}{|c|c|c|c|c|}
\hline \multirow{2}{*}{\multicolumn{2}{|c|}{$\begin{array}{c}\text { Self- } \\
\text { Esteem }\end{array}$}} & Depression & \multirow[t]{2}{*}{ Delinquency } & $\begin{array}{l}\text { Alcohol } \\
\text { Problems }\end{array}$ \\
\hline & & & & \\
\hline \multicolumn{5}{|c|}{ Permissive } \\
\hline First & -0.60 & $-0.28 * *$ & $-0.94^{\mathrm{a}, * * *}$ & $-0.51^{+}$ \\
\hline Second & $-1.04^{*}$ & $-0.14^{+}$ & $-0.43^{* *}$ & -0.17 \\
\hline Third & - & - & - & - \\
\hline \multicolumn{5}{|l|}{ Disengaged } \\
\hline First & 0.49 & 0.03 & $-0.90^{*}$ & $-1.06^{*}$ \\
\hline Second & $2.82^{* *}$ & 0.21 & -0.19 & $-0.87^{*}$ \\
\hline Third & - & - & - & - \\
\hline \multicolumn{5}{|l|}{ Authoritative } \\
\hline First & $-1.67^{*}$ & 0.02 & 0.20 & -0.22 \\
\hline Second & -0.59 & -0.09 & 0.01 & -0.02 \\
\hline Third & - & - & - & - \\
\hline \multicolumn{5}{|l|}{ Authoritarian } \\
\hline First & 0.71 & -0.29 & 0.38 & $-0.56^{\mathrm{b}}$ \\
\hline Second & 0.23 & -0.01 & $1.05^{* *}$ & 0.06 \\
\hline Third & - & - & - & - \\
\hline Male & 0.41 & $-0.26^{* * *}$ & $0.29^{*}$ & 0.19 \\
\hline Age & 0.09 & -0.01 & $-0.07^{*}$ & 0.04 \\
\hline \multicolumn{5}{|l|}{ Family structure } \\
\hline Single mother & -0.21 & 0.01 & $0.27^{+}$ & $0.28^{*}$ \\
\hline Stepfamily & -0.03 & 0.04 & 0.01 & 0.39 \\
\hline Siblings & 0.14 & $-0.03^{*}$ & -0.04 & 0.01 \\
\hline \multicolumn{5}{|l|}{ Parent education } \\
\hline$<$ High school & -0.27 & 0.01 & 0.24 & 0.25 \\
\hline Some college & 0.27 & -0.16 & $0.46^{*}$ & 0.23 \\
\hline$\geq$ Bachelor's & 1.10 & -0.15 & 0.07 & 0.04 \\
\hline Public assistance & 0.58 & -0.08 & 0.02 & -0.05 \\
\hline \multicolumn{5}{|l|}{ Neighborhood } \\
\hline Good quality & -0.03 & 0.00 & 0.03 & -0.09 \\
\hline Poor quality & -0.40 & 0.02 & 0.16 & -0.14 \\
\hline Intercept & $18.12^{* * *}$ & 1.26 & $2.89 * * *$ & -0.11 \\
\hline$R^{2}$ & .20 & .15 & .16 & .10 \\
\hline$n$ & 802 & 804 & 792 & 802 \\
\hline
\end{tabular}

a The first is significantly different from the second at $p<.05$.

$\mathrm{b}$ The first is significantly different from the second at $p<.01$.

${ }^{+} p \leq .1 ;{ }^{*} p \leq .05 ;{ }^{* *} p \leq .01 ;{ }^{* * *} p \leq .001$ 
Permissive parenting. As Table 6 shows, among youth with permissive mothers, those with U.S.-born parents had greater self-esteem than did those with immigrant parents but also higher mean levels of depression, delinquency, and alcohol problems. Teens with permissive mothers exhibit generational patterns that are similar to overall patterns for behavior problems and self-esteem. That is, third-generation teens have higher self-esteem as well as higher delinquency and alcohol-related problems than do the children of immigrant parents. In addition, although there are no general generational differences in depression, it is higher among third-generation teens with permissive mothers than it is among first- and second-generation teens.

Disengaged parenting. As the interaction models show, among youth who had disengaged mothers, third-generation teens had lower self-esteem than second-generation teens, contradicting the overall generational pattern of self-esteem. The patterns for delinquency and alcohol problems were similar to the overall generational patterns; third-generation teens had higher levels of these problem behaviors than did the children of immigrant parents. Levels of depression did not vary across generations for teens with disengaged mothers. Given the relatively high mean overall levels of depression among teens in this group, the lack of generational differences suggests that teens with disengaged mothers had uniformly high levels of depression.

Authoritative parenting. With the exception of self-esteem, the outcomes of interest did not vary by generation among youth with mothers who practiced an authoritative style of parenting. Given the overall low levels of depression, delinquency, and alcohol problems among teens of authoritative mothers, this finding suggests that teens in this group have uniformly low levels of these harmful outcomes across generations. Thirdgeneration teens of authoritative mothers had higher mean levels of selfesteem than did immigrant youth with similar mothers, a pattern that mirrors the general pattern.

Authoritarian parenting. There were no generational differences in self- esteem and depression among teens with authoritarian mothers. Because teens with authoritarian mothers had the lowest mean levels of selfesteem and the highest mean levels of depression, the lack of generational differences within this group of youth suggests that these teens had uniformly lower self-esteem and higher depression than did teens whose 
mothers employed other parenting styles. Second-generation teens had higher rates of delinquency than third-generation teens had and higher rates of alcohol problems than immigrant teens had.

\section{Discussion}

Research on adolescents from immigrant families has documented the association between immigrant generation and negative outcomes, such as risky and antisocial behaviors and poor mental health (e.g., Harris, 2000). If true, this is a disheartening and particularly poignant situation because one of the primary reasons that immigrants move to the United States is to improve their children's opportunities and life chances. There is much concern that as the duration of exposure to U.S. society and level of acculturation rise, children exhibit increasingly poor outcomes, similar to those of children from the majority culture. The overall generational patterns of adolescent well-being that we found are similar to those found in the literature. Higher-generation teens have higher self-esteem than do the children of immigrant parents, but behavior problems increase with generation. Levels of depression were essentially flat across generations. The analyses presented above suggest that at least among youth of Mexican origin, these patterns occur only for the substantial subset of youth whose parents practice nonauthoritative parenting styles.

Most work that strives to document and explain the effects of generational status and acculturation on the well-being of Latino and Asian youth focuses on the acculturation of the young people themselves. Our findings suggest that parents' own acculturation plays a crucial role in their children's well-being; that is, parenting patterns differ by place of birth. Half of immigrant parents utilized parenting styles based on high levels of control, whereas almost two thirds of native-born parents had parenting styles characterized by granting greater autonomy to their adolescents. At the same time, the proportion of teens parented by mothers whose styles incorporate high levels of support rose to almost 9 in 10 children of native parents, from 3 in 4 children of immigrant parents. Thus, U.S.-born Mexican parents are more likely to practice permissive parenting styles and less likely to be authoritative in style than are those born in Mexico. This generational shift results in a distribution of parenting styles among U.S.-born parents of Mexican origin that is similar to the distribution that exists among U.S.-born White parents. That is, the parents of third-generation Mexicans (and higher) tend to practice a more American style of parenting as a result of their own upbringing in the United States. 
Within groups characterized by parenting style, different generational patterns exist. Behavioral outcomes and depression were worse for thirdgeneration teens from permissive families than for first- and second-generation teens from similar families. Generational patterns in behavioral outcomes were similar for teens of disengaged parents, whereas thirdgeneration teens of authoritarian parents had fewer behavioral problems than either first- or second-generation teens of similar parents. Teens with authoritative parents had markedly different generational patterns. As was found for teens from permissive parents, third-generation teens had higher levels of self-esteem than those with immigrant parents had. Otherwise, levels of depressive symptoms, delinquency, and alcohol-related problems were uniformly low across generations, as would be expected given past research that links authoritative parenting style to positive behavioral and mental health outcomes.

We analyzed two forces that function to shape generational problem behavior patterns of Mexican-origin youth. The level of control that parents exercise over their teens' behavior is related to the risk of engaging in risky behaviors (Browning, Leventhal, \& Brooks-Gunn, 2005; Cota-Robles \& Gamble, 2006; Harris \& Ryan, 2001; Stice \& Barrera, 1995; van der Vorst, Engels, Meeus, \& Dekovic, 2006; Wright, Williamson, \& Henderson, 2006). Higher percentages of immigrant parents, as compared to native parents, exercise firm control over their adolescents, an aspect of parenting related to behavioral outcomes. At the same time, third-generation teens with permissive and disengaged parents - the parenting categories defined by high levels of autonomy granting - have worse outcomes than do their counterparts with immigrant parents. This finding suggests that third- generation teens, who are more acculturated and therefore more exposed to the attitudes of the larger teen culture, are less likely to experience the firm control that could counteract these outside influences (Deosaransingh et al., 1995). The lower likelihood of having parents who exercise firm control, combined with the greater exposure to negative influences, results in a higher chance of worse behavior outcomes among third-generation teens.

In contrast, children of authoritative and authoritarian native parents, characterized by high levels of control, are not more likely than their firstand second-generation counterparts to be engaged in delinquency or have alcohol-related problems. Moreover, their rates of problem behavior are low overall, suggesting that the lack of generational change among teens of authoritative parents or that of improvement among authoritarian parents reflects uniformly low levels of problem behavior across generations. Such parents account for only one third of the parents of third-generation teens, a fraction quite similar to that of U.S.-born White parents. Never- 
theless, their exercise of parental control appears to protect their sons and daughters from negative influences.

A somewhat similar pattern was found for self-esteem. Parental support and warmth are important predictors of young people's emotional health. The proportion of supportive mothers (permissive and authoritative) among third-generation teens was higher than it was among their first- and second- generation peers. Within the group with supportive mothers, levels of self- esteem were higher among third-generation teens. This finding suggests that the children of native-born parents benefit more from parental support than do the parents of immigrant teens, at least in terms of self-esteem. Why this might be is not apparent. The higher levels of self-esteem among third- generation teens with permissive or authoritative parents, coupled with the higher percentage of teens in this generation with such parents, result in higher overall levels of self-esteem among the teens of U.S.-born parents when compared to those of immigrant parents.

The findings for depression differ from those for self-esteem. Overall, depression levels are stable across generations, a pattern found for teens with disengaged, authoritative, and authoritarian parents. It should be noted that although levels might not differ among generations for these three groups, the overall levels of adolescent depression do. Teens with authoritative parents had low levels overall; therefore, uniform levels across generation indicate that each generation experienced low mean levels of depression. The opposite situation exists for teens whose mothers showed them low levels of support and warmth. In this case, no generational changes signal uniformly high levels of depression. Third-generation teens with permissive parents experienced higher levels of depression than did their peers with immigrant parents. Evidently, the combination of high support and low control does not shield highly acculturated teens from factors that promote depression. Conversely, this parenting style is more effective in protecting teens when exercised by immigrant parents. The reasons for this pattern are not clear; the answers may lie in a greater understanding of the extrafamilial environments in which teens and their families live and how they are distributed across generation and parenting style.

Another question focuses on the differences between the two parenting groups characterized by high levels of support-permissive and authoritative. The difference between these two groups involves the level of control that their children perceive them as exerting, suggesting that this difference explains the starkly different generational patterns. The results suggest that permissive parenting generally has a less negative effect on teens with immigrant parents than it does on higher-generation youth. It is possible that first- and second-generation youth experience more control and oversight 
from other relatives and community members than do third-generation teens because the former have closer ties to extended family and are more likely than the offspring of U.S.-born parents to live in close-knit immigrant communities. These extraparental sources of control may serve to protect teens from involvement in risky and unhealthy behaviors. In addition, because permissive parents are less common among first- and second-generation youth, the peers of these teens are more likely to have parents who wield greater levels of control and monitoring. This may indirectly affect the behavior of teens with permissive parents by limiting opportunities for misconduct and peer pressure to participate (Gray \& Steinberg, 1999). Conversely, the peers of third- and higher-generation youth are more likely to have permissive parents who grant them greater leeway.

The etiology of the parenting styles reported by the youth in the sample is not known. It is possible that mothers who do not exercise adequate oversight over their children (those in the disengaged and permissive categories) do not parent in this manner by choice. They may be struggling with mental health challenges that prevent them from taking a more active role in their child's upbringing (e.g., depression, substance abuse). Moreover, parents' behaviors and mental health challenges may be reflected in their children's behavior and emotional well-being.

The age range of the sample encompasses 7 years, a somewhat wide range given the number and importance of changes that take place during early and late adolescence. The developmental differences between 12- and 18-year-olds suggest that differences in the relationships between parenting, generations, and outcomes might have been masked by the analyses. Although this is possible, it was not possible to retain sufficient cell sizes after dividing the sample into younger and older strata. Thus, although the analyses speak to relationships between generational patterns and well-being within type of parenting net of age, they cannot be interpreted as comparing possible differences in these relationships between older and younger teens.

One component of the parenting measure, parental control, was based on a measure with a relatively low Cronbach's alpha. This is partially due to the somewhat small number of items forming the measure. Although an ideal measure would have greater reliability, this measure is still useful and detracts little from the overall findings.

Finally, this study did not address the meaning of the parenting measures. It is possible that first-, second-, and third-generation youth would rate identical parental behaviors differently. For example, what an immigrant teen views as being permissive may seem rather restrictive to a higher-generation, more acculturated teen. A worthwhile line of inquiry 
would explore the effects of cultural adaptation on the meaning of measures of parenting to parents and adolescents, as well as other factors that influence young people's behavior.

This study supports the proposition that generational changes in parenting styles appear to play a role in generational patterns of emotional well-being and problem behaviors of Mexican-origin youth. This implies that it is useful to take parental acculturation levels and experiences into account when predicting and explaining the well-being of youth of Mexican origin. A broadening of the focus of factors that shape these young people's outcomes - particularly, those born to U.S.-born parents - to include parenting practices and styles will increase the accuracy of our understanding of those with poor emotional well-being or behavior problems. This understanding, if incorporated into approaches designed to address these issues, will contribute to greater success in helping adolescents develop in a healthy manner.

The results of this study prompt avenues for future research. One next step is to investigate what predicts parenting styles of U.S.-born parents of Mexican origin and to explore the reasons why some parents continue to hew to practices more common among immigrant parents whereas the parenting styles of others come to resemble those of the majority culture. The reasons for these differences potentially have ramifications for family dynamics and childrearing practices that are important to understand. Finally, future research should examine whether these patterns are found for immigrant groups of other national origins. The ability to compare parenting patterns across national-origin groups would reveal whether the patterns found here for parents of Mexican origin represent a more general immigrant adjustment or acculturation process or whether they are specific to one group's experiences in the United States.

\section{References}

Bankston, L. C., III, \& Zhou, M. (2002). Being well vs. doing well: Self-esteem and school performance among immigrant and nonimmigrant racial and ethnic groups. International Migration Review, 36(2), 389-415.

Baumrind, D. (1991). The influence of parenting style on adolescent competence and sub stance use. Journal of Early Adolescence, 11(1), 56-95.

Bearman, P. S., Jones, J., \& Udry, J. R. (1997). The National Longitudinal Study of Adolescent Health: Study design. Retrieved August 12, 2007, from http://www.cpc.unc. edu/projects/addhealth/design

Brown, B. B., Mounts, N., Lamborn, S. D., \& Steinberg, L. (1993). Parenting practices and peer group affiliation in adolescence. Child Development, 64(2), 467-482.

Browning, C. R., Leventhal, T., \& Brooks-Gunn, J. (2005). Sexual initiation in early adolescence: The nexus of parental and community control. American Sociological Review, 70(5), 758-778. 
Bulcroft, R. A., Carmody, D. C., \& Bulcroft, K. A. (1996). Patterns of parental independence giving to adolescents: Variations by race, age, and gender of child. Journal of Marriage and Family, 58, 866-883.

Buriel, R. (1993). Childrearing orientations in Mexican American families: The influence of generation and sociocultural factors. Journal of Marriage and Family, 55, 987-1000.

Buriel, R., \& De Ment, T. (1997). Immigration and sociocultural change in Mexican, Chinese and Vietnamese American families. In A. Booth, A. C. Crouter, \& N. Landale (Eds.), Immigration and the family: Research and policy on U.S. immigrants (pp. 165-200). Mahwah, NJ: Lawrence Erlbaum.

Burnam, M. A., Hough, R. L., Karno, M., Escobar, J. I., \& Telles, C. A. (1987). Acculturation and lifetime prevalence of psychiatric disorders among Mexican Americans in Los Angeles. Journal of Health and Social Behavior, 28(1), 89-102.

Conger, R. D., Conger, K. J., Elder, G. H., Jr., Lorenz, F. O., Simons, R. L., \& Whitbeck, L. B. (1993). Family economic stress and adjustment of early adolescent girls. Developmental Psychology, 29(2), 206-219.

Cota-Robles, S., \& Gamble, W. (2006). Parent-adolescent processes and reduced risk for delinquency: The effect of gender for Mexican American adolescents. Youth \& Society, 37(4), 375-392.

Crockett, L. J., Randall, B. A., Shen, Y., Russell, S. T., \& Driscoll, A. K. (2005). Measurement equivalence of the Center for Epidemiological Studies Depression Scale for Latino and Anglo adolescents: A national study. Journal of Consulting and Clinical Psychology, 73(1), 47-58.

Delgado-Gaitan, C. (1994). Socializing young children in Mexican-American families: An intergenerational perspective. In P. M. Greenfield \& R. R. Cocking (Eds.), Cross-cultural roots of minority child development (pp. 55-86). Hillsdale, NJ: Lawrence Erlbaum.

Denner, J., Kirby, D., Coyle, K., \& Brindis, C. (2001). The protective role of social capital and cultural norms in Latino communities: A study of adolescent births. Hispanic Journal of Behavioral Sciences, 23(1), 3-21.

Deosaransingh, K., Moreno, C., Woodruff, S. I., Sallis, J. F., Vargas, R., \& Elder, J. P. (1995). Acculturation and smoking in Latino youth. Health Values, 19(3), 43-52.

Dinh, K. T., Roosa, M. W., Tein, J.-Y., \& Lopez, V. A. (2002). The relationship between acculturation and problem behavior proneness in a Hispanic youth sample: A longitudinal mediation model. Journal of Abnormal Child Psychology, 30(3), 295-309.

Ellis, G. J., Thomas, D. L., \& Rollins, B. C. (1976). Measuring parental support: The interrelationship of three measures. Journal of Marriage and the Family, 38(4), 713-722.

Epstein, J. A., Botvin, G. J., \& Diaz, T. (1998). Linguistic acculturation and gender effects on smoking among Hispanic youth. Preventive Medicine, 27, 583-589.

Epstein, J. A., Botvin, G. J., \& Diaz, T. (2001). Linguistic acculturation associated with higher marijuana and polydrug use among Hispanic adolescents. Substance Use \& Misuse, 36(4), 477-499.

Fuligni, A. J., Tseng, V., \& Lam, M. (1999). Attitudes toward family obligations among American adolescents with Asian, Latin American, and European backgrounds. Child Development, 70(4), 1030-1044.

Ge, X., Best, K. M., Conger, R. D., \& Simons, R. L. (1996). Parenting behaviors and the occurrence and co-occurrence of adolescent depressive symptoms and conduct problems. Developmental Psychology, 32, 717-731.

Gil, A. G., Wagner, E. F., \& Vega, W. A. (2000). Acculturation, familism and alcohol use among Latino adolescent males: Longitudinal relations. Journal of Community Psychology, 28(4), 443-458.

Gordon, M. M. (1964). Assimilation in American life: The role of race, religion and national origins. Oxford, UK: Oxford University Press.

Gray, M., \& Steinberg, L. (1999). Unpacking authoritative parenting: Reassessing a multidimensional construct. Journal of Marriage and Family, 61(3), 574-587. 
Handlin, O. (1951). The uprooted: The epic story of the great migrations that made the American people. New York: Grosset \& Dunlap.

Harker, K. (2001). Immigrant generation, assimilation and adolescent psychological wellbeing. Social Forces, 79(4), 969-1004.

Harris, K. M. (2000). The health status and risk behaviors of adolescents in immigrant families. In D. J. Hernandez (Ed.), Children of immigrants: Health, adjustment, and public assistance (pp. 286-347). Washington, DC: National Academy Press.

Harris, K. M., \& Ryan, S. (2001, March). Family processes, neighborhood context and adolescent risk behaviors. Paper presented at the annual meeting of the Population Association of America meetings, Washington, DC.

Hogan, D. P., \& Kitagawa, E. M. (1985). The impact of social status, family structure, and neighborhood on the fertility of Black adolescents. American Journal of Sociology, 90(4), 825-855.

Jacobson, K. C., \& Crockett, L. J. (2000). Parental monitoring and adolescent adjustment: An ecological perspective. Journal of Research on Adolescence, 10(1), 65-97.

Jamieson, A., Curry, A., \& Martinez, G. (2001). School enrollment in the United States: Social and economic characteristics of students: October, 1999 (Current Population Reports No. P20-533). Washington, DC: U.S. Census Bureau.

Kao, G. (2004). Parental influences on the educational outcomes of immigrant youth. International Migration Review, 38(2), 427-449.

Kaplan, C. P., Erickson, P., \& Juarez-Reyes, M. (2002). Acculturation, gender role orientation, and reproductive risk-taking behavior among Latina adolescent family planning clients. Journal of Adolescent Research, 17(2), 103-121.

Kaplan, M. S., \& Marks, G. (1990). Adverse effects of acculturation: Psychological distress among Mexican American young adults. Social Science and Medicine, 31(12), 1313-1319.

Kapinus, C. A., \& Gorman, B. K. (2004). Closeness with parents and perceived consequences of pregnancy among male and female adolescents. Sociological Quarterly, 45(4), 691-717.

Kurdek, L. A., \& Fine, M. A. (1994). Family acceptance and family control as predictors of adjustment in young adolescents: Linear, curvilinear, or interactive effects? Child Development, 65(4), 1137-1146.

Lamborn, S. D., Mounts, N. S., Steinberg, L., \& Dornbusch, S. M. (1991). Patterns of competence and adjustment among adolescents from authoritative, authoritarian, indulgent, and neglectful families. Child Development, 62, 1049-1065.

Maccoby, E. E., \& Martin, J. (1983). Socialization in the context of the family: Parent-child interaction. In E. M. Hetherington (Ed.), Handbook of child psychology: Vol. 4. Socialization, personality, and social development (pp. 1-101). New York: John Wiley.

Newcomer, S., \& Udry, J. R. (1987). Parental marital status effects on adolescent sexual behavior. Journal of Marriage \& the Family, 49(2), 235-240.

Patterson, G. R., \& Stouthamer-Loeber, M. (1984). The correlation of family management practices and delinquency. Child Development, 55(4), 1299-1307.

Pong, S., Hao, L., \& Gardner, E. (2005). The roles of parenting styles and social capital in the school performance of immigrant Asian and Hispanic adolescents. Social Science Quarterly, 86(4), 928-950.

Radloff, L. S. (1977). The CES-D Scale: A self-report depression scale for research in the general population. Applied Psychological Measurement, 1(3), 385-401.

Radziszewska, B., Richardson, J. L., Dent, C. W., \& Flay, B. R. (1996). Parenting style and adolescent depressive symptoms, smoking, and academic achievement: Ethnic, gender and SES differences. Journal of Behavioral Medicine, 19(3), 289-305.

Regnerus, M. D., \& Burdette, A. (2006). Religious change and adolescent family dynamics. Sociological Quarterly, 47(1), 175-194. 
Rosenberg, M. (1989). Society and the adolescent self-image (Rev. ed.). Middletown, CT: Wesleyan University Press.

Sam, D. L. (2000). Psychological adaptation of adolescents with immigrant backgrounds. Journal of Social Psychology, 140(1), 5-25.

Samaniego, R. Y., \& Gonzales, N. A. (1999). Multiple mediators of the effects of acculturation status on delinquency for Mexican American adolescents. American Journal of Community Psychology, 27(2), 189-210.

Shakib, S., Mouttapa, M., Johnson, C. A., Ritt-Olson, A., Trinidad, D. R., Gallaher, P. E., et al. (2003). Ethnic variation in parenting characteristics and adolescent smoking. Journal of Adolescent Health, 33(2), 88-97.

Shrout, P. E., Canino, G. J., Bird, H. R., Rubio-Stipec, M., Bravo, M., \& Burnam, M. A. (1992). Mental health status among Puerto Ricans, Mexican Americans, and non-Hispanic Whites. American Journal of Community Psychology, 20(6), 729-752.

Shucksmith, J., Hendry, L. B., \& Glendinning, A. (1995). Models of parenting: Implications for adolescent well-being within different types of family contexts. Journal of Adolescence, 18, 253-270.

Steinberg, L. (2001). We know some things: Parent-adolescent relationships in retrospect and prospect. Journal of Research on Adolescence, 11(1), 1-19.

Steinberg, L., Mounts, N. S., Lamborn, S. D., \& Dornbusch, S. M. (1991). Authoritative parenting and adolescent adjustment across varied ecological niches. Journal of Research on Adolescence, 1(1), 19-36.

Stice, E., \& Barrera, M. (1995). A longitudinal examination of the reciprocal relations between perceived parenting and adolescents' substance use and externalizing behaviors. Developmental Psychology, 31(2), 322-334.

U.S. Census Bureau. (2000). Projections of the total resident population by 5-year age groups, race, and Hispanic origin with special age categories: Middle series, 1999 to 2000 (Tables NP-T4-A through NP-T4-F). Washington, DC: Author. Retrieved from August 12, 2007, www.census.gov/population/www/projections/natsum-T3.html

van der Horst, H., Engels, R., Meeus, W., \& Dekovic, M. (2006). Parental attachment, parental control, and early development of alcohol use: A longitudinal study. Psychology of Addictive Behaviors, 20(2), 107-116.

Varela, R. E., Vernberg, E. M., Sanchez-Sosa, J. J., Riveros, A., Mitchell, M., \& Mashunkashey, J. (2004). Parenting style of Mexican, Mexican American, and Caucasian- non-Hispanic families: Social context and cultural influences. Journal of Family Psychology, 18(4), 651-657.

Warner, W. L., \& Srole, L. (1945). The social systems of American ethnic groups. New Haven, CT: Yale University Press.

Wolfradt, U., Hemple, S., \& Miles, J. M. V. (2003). Perceived parenting styles, depersonalisation, anxiety and coping behaviour in adolescents. Personality and Individual Differences, 34, 521-532.

Wright, D., Williamson, L., \& Henderson, M. (2006). Parental influences on young people's sexual behaviour: A longitudinal analysis. Journal of Adolescence, 29(4), 473-494.

Zhou, M. (1994). Social capital and the adaptation of the second generation: The case of Vietnamese youth in New Orleans. International Migration Review, 28(4), 821-845. 